http://dx.doi.org/10.1590/2176-457335092

\title{
Vozes em confronto no Núcleo Docente Estruturante de cursos de Letras: entre o prescrito e a prática institucionalizada / Voices in Confrontation in Structuring Professoriate Groups of Undergraduate Language Teacher Education Programs: Between the Prescribed and the Institutionalized Practice
}

Jozanes Assunção Nunes*

\section{RESUMO}

O presente artigo tem como objetivo analisar as reações-respostas de professores do Núcleo Docente Estruturante (NDE) de Cursos de Letras de uma universidade pública aos discursos consignados nos documentos oficiais da educação que dispõem sobre o Núcleo nas instituições de ensino, focalizando as relações de tensão existentes entre os discursos envolvidos na interação verbal. Os fundamentos da Teoria Dialógica do Discurso, de viés bakhtiniano, orientam o estudo, favorecendo o debate em torno das refrações e revalorizações dos discursos legais relacionados à criação do NDE no âmbito dos cursos de graduação. A análise dialógica revela que os enunciados dos sujeitos da pesquisa interagem com as vozes oficiais que determinam a criação do NDE e, de algum modo, são respostas a elas, tanto acolhendo-as, como também alterando-as, recusando-as, desprezando-as, num contexto em que os cursos de Letras seriam avaliados por comissões de avaliadores do Ministério da Educação.

PALAVRAS-CHAVE: Núcleo Docente Estruturante; Discursos oficiais; Discursos de professores; Dialogismo; Responsividade

\section{ABSTRACT}

The present article aims to analyze the reactions-responses of professors who belong to a Structuring Professoriate Group (SPG) from a public university's Undergraduate Language Teacher Education Programs to discourses in official education documents that discuss the SPGs in higher education institutions. It focuses on the relations of tensions between discourses involved in verbal interactions. Bakhtinian Dialogical Discourse Theory fundamentals guide the study, favoring the debate around refractions and revaluations of legal discourses related to the SPG creation in the scope of undergraduate programs. A dialogical analysis reveals that the utterances of the research subjects interact with the official voices which determine the SPG creation and, somehow, are answers to them, welcoming them, as well as altering them, refusing them and disregarding them, in a context in which the Language programs would be assessed by the Ministry of Education evaluation committee.

KEYWORDS: Structuring Professoriate Group; Official Discourses; Professors' Discourses; Dialogism; Responsiveness

\footnotetext{
* Universidade Federal de Mato Grosso - UFMT, Cuiabá, Mato Grosso, Brasil; egressa do PEPG em LAEL/PUC-SP, São Paulo, São Paulo, Brasil; jozanes@globo.com
} 


\section{Introdução}

Este artigo apresenta parte dos resultados de uma pesquisa de doutorado que buscou compreender a complexidade do processo de reestruturação de Cursos de Letras na esfera acadêmica (NUNES, 2017), tomando como base epistêmica e metodológica a teoria advinda dos estudos bakhtinianos, intitulada por Brait (2008) de "Análise Dialógica do Discurso". Fazendo um recorte nessa pesquisa mais ampla, o objetivo aqui é analisar as reações-respostas de professores do Núcleo Docente Estruturante (NDE) de Cursos de Letras de uma universidade pública aos discursos consignados nos documentos oficiais que dispõem sobre esse Núcleo no âmbito dos cursos de graduação, a saber, o Parecer CONAES n. 4/2010 e a Resolução CONAES n. 1/2010, focalizando as relações de tensão existentes entre os discursos envolvidos na interação verbal.

O NDE é uma instância colegiada constituída por um grupo de professores com atribuições de formulação e acompanhamento do Projeto Pedagógico de um curso de graduação, formalmente indicado pela instituição (BRASIL, 2010a). Na universidade pesquisada, o NDE dos Cursos de Letras foi criado ${ }^{1}$ num contexto em que esses cursos seriam avaliados por comissões de especialistas do Instituto Nacional de Estudos e Pesquisas Educacionais Anísio Teixeira (INEP/MEC), devido ao Conceito Preliminar de Curso (CPC) insatisfatório que obtiveram no Exame Nacional de Desempenho de Estudantes (ENADE) de 2011.

O estudo parte do pressuposto de que existe um embate de forças políticoideológicas que permeiam os enunciados dos sujeitos da pesquisa acerca da configuração do NDE, provocando as mais diversas respostas aos discursos oficiais, podendo ser não apenas de adesão, mas também de recusa, crítica e revalorização, mesmo num contexto em que os cursos seriam avaliados por comissões de avaliadores do MEC.

Com vistas à consecução do objetivo proposto, organizamos o artigo em quatro seções. Na primeira, discorremos sobre o embasamento teórico-metodológico que ancora a pesquisa; na segunda, discutimos as condições de produção dos enunciados dos

\footnotetext{
${ }^{1}$ Nunes (2016) realiza uma análise dialógica do Parecer CONAES n. 4/2010 na sua relação com a Resolução CONAES n. 1/2010, desvelando as estratégias utilizadas pelo sujeito enunciador para convencer os sujeitos das instâncias acadêmicas a criarem o NDE nos cursos de graduação.
} 
sujeitos da pesquisa; na terceira, refletimos sobre o Núcleo Docente Estruturante dos Cursos de Letras na percepção de seus integrantes, focalizando tanto a configuração do NDE no processo de reestruturação curricular quanto o papel de seus integrantes, e, por fim, concluímos nossa trajetória com as considerações finais.

\section{Aspectos teórico-metodológicos}

À luz dos estudos de Bakhtin e do Círculo, neste trabalho, partimos da compreensão de que todo enunciado se realiza numa dada situação comunicativa concreta, num determinado contexto histórico-social, por sujeitos com intenções comunicativas distintas e que agem e interagem por meio da língua. Sob essa ótica, o enunciado, enquanto materialidade discursiva, não se fecha em si mesmo, visto que se constitui como tal no interminável diálogo entre discursos já-ditos ou ainda não ditos, abrigando uma multiplicidade de vozes, ou seja, posições ideológicas, que estabelecem entre si relações de acordo ou desacordo, aceitação ou recusa, harmonia ou conflito.

Faraco (2010, p.69), com base no pensamento bakhtiniano, destaca que o diálogo, no sentido amplo do termo, deve ser entendido como um vasto espaço de luta entre as vozes sociais (uma espécie de guerra dos discursos), no qual atuam forças centrípetas e forças centrífugas. Por certo, ao discutir a questão do dialogismo, Bakhtin (2014) afirma que as forças centrípetas e centrífugas, que incidem sobre a língua, projetam-se no sentido de centralização e de dispersão, estando sempre em confronto. Nesse prisma, enquanto as forças centrípetas buscam instituir certa centralização da realidade, as centrífugas buscam desestabilizar a ordem centralizadora, visando à ruptura. Faz-se importante destacar, entretanto, que, qualquer que seja a produção e seu respectivo contexto sócio-histórico, as duas forças sempre estarão em estado dialógico de interação, constituindo-se uma em função da outra, em uma perspectiva de embate que somente é possível avaliar na realidade concreta da língua.

Levando em consideração tal conceito, estabelecemos neste artigo uma analogia entre as vozes oficiais que tratam da criação do NDE e forças centrípetas, por buscarem uma homogeneização do processo de reestruturação de curso, e outra entre vozes que apresentam uma perspectiva axiológica oposta às vozes oficiais e forças centrífugas. Os documentos, como o Parecer n. 4/2010 e a Resolução n. 1/2010 da Comissão Nacional 
de Avaliação da Educação Superior (CONAES), foram elaborados com a finalidade de superar os diversos discursos que compõem o processo de reforma curricular, opondolhe barreiras, assim como ocorre com a categoria da linguagem única, de que trata Bakhtin (2014).

Ao ser declarado, o enunciado espera uma resposta. Como salienta Bakhtin (2011, p.271), “toda compreensão da fala viva, do enunciado vivo é de natureza ativamente responsiva (embora o grau desse ativismo seja bastante diverso); toda compreensão é prenhe de resposta, e nessa ou naquela forma a gera obrigatoriamente: o ouvinte se torna falante". Assim, não há compreensão sem uma antipalavra, no dizer de Volóchinov (2017, p.232).

Considerando que a natureza do enunciado é dialógica, a relação discursoresposta dos integrantes do NDE, no diálogo com os documentos da CONAES que tratam da criação do Núcleo, será analisada para que os sentidos sejam constituídos, visto que somente no diálogo eles são gerados. Desse modo, os sentidos aflorarão a partir do estabelecimento das relações dialógicas.

Cabe registrar que as relações dialógicas existentes entre os discursos podem ser harmônicas ou polêmicas, abertamente polêmicas ou veladamente polêmicas, apreendidas a partir do ponto de vista do observador, do pesquisador. Para Bakhtin (2013, p.224-225), a polêmica aberta ocorre quando o objeto de refutação é o próprio discurso do outro. Na polêmica velada, diferentemente, "a ideia do outro não entra 'pessoalmente' no discurso, apenas reflete neste, determinando-lhe o tom e a significação".

Com base nesses preceitos, analisamos, neste trabalho, a responsividade dos integrantes do Núcleo Docente Estruturante dos cursos de Letras de uma universidade pública aos discursos oficiais, no que tange à configuração e ao desenvolvimento desse Núcleo, a partir de dados do questionário aplicado ${ }^{2}$ e da entrevista semiestruturada realizada de forma coletiva com os sujeitos da pesquisa ${ }^{3}$.

\footnotetext{
${ }^{2} \mathrm{O}$ questionário foi aplicado para coletar dados sobre o perfil dos participantes e suas percepções sobre o NDE que integram.

${ }^{3}$ Buscamos, com a entrevista, identificar tendências e padrões de respostas relevantes, relacionados à problemática estudada, focalizando a interação dos sujeitos discursivos. Participaram da entrevista os cinco professores integrantes do NDE, com idade entre 40 e 65 anos, que tinham a função de reestruturar os cursos de Letras. Para a transcrição dos dados, seguimos algumas das codificações apresentadas por Marcuschi (2000). Os códigos usados são: .... fala intercalada dos professores; (+) pausa breve nos fluxos
} 
Formulamos nossa trajetória de pesquisa a partir da orientação de Volóchinov (2017, p.220), pela qual, primeiramente, é necessário compreender a "interação discursiva" que se dá numa situação histórica, concreta, observando o gênero a que pertencem os discursos, para, por fim, realizar a análise das formas da língua em sua concepção linguística habitual.

Partindo, então, dessas coordenadas, passemos à discussão dos enunciados dos integrantes do NDE na sua relação com os enunciados da CONAES, discorrendo, primeiramente, sobre seu contexto de produção, pois, como afirmam Brait e Pistori (2012, p.378), “diante de um gênero, e dos textos que o constituem, é necessário considerar suas dimensões (interna/externa), de maneira a explicitar as inter-relações dialógicas e valorativas".

\section{Letras em tempo de SINAES: o contexto de produção dos discursos dos professores do NDE}

A reestruturação dos cursos de Letras da instituição pesquisada (Cursos de Letras Português e Literatura, Português e Inglês, Português e Francês e Português e Espanhol) teve início em janeiro de 2013. Um dos fatores que impulsionaram tal reestruturação foi o desempenho insuficiente dos cursos no Conceito Preliminar de Curso (CPC), em 2011. O CPC é um indicador de qualidade dos cursos de graduação (avaliados numa escala de 1 a 5), que compõe o Sistema Nacional de Avaliação da Educação Superior (SINAES), criado pela Lei n. 10.861/2004. Com o objetivo de assegurar o processo nacional de avaliação das Instituições de Educação Superior (IES), o SINAES conta com três componentes básicos: a avaliação das instituições, dos cursos e do desempenho dos estudantes.

Os cursos de graduação com CPC inferior a três são submetidos a medidas cautelares. Foi o que ocorreu com os cursos de Letras da instituição pesquisada. Como não obtiveram CPC satisfatório no Exame Nacional de Desempenho dos Estudantes (ENADE) de 2011, tiveram, juntamente com a instituição, de firmar protocolos de compromisso com o MEC, a fim de sanear as deficiências identificadas pela avaliação.

de fala; (++) pausa longa nos fluxos de fala; (( )) comentários da pesquisadora; MAIÚSCULAS, ênfase ou acento forte. Além desses códigos, utilizamos: E para entrevistadora; PO1 .... P02, para os professores. 
Ademais, todos os cursos receberam visita in loco de uma comissão de avaliadores do Instituto Nacional de Estudos e Pesquisas Educacionais Anísio Teixeira (INEP), que teve como objetivo verificar o cumprimento do protocolo.

Nesse contexto, em 2013, seguindo as determinações da Comissão Nacional de Avaliação de Cursos (CONAES), os cursos de Letras criaram o Núcleo Docente Estruturante (NDE) para que, entre outras atribuições, seus membros realizassem a reformulação dos Projetos Pedagógicos dos Cursos, que seriam avaliados na visita in loco dos examinadores do INEP.

No que concerne à criação do órgão, constatamos que há certa conformidade com as determinações da CONAES manifestas na Resolução CNE/CP n. 1/2010, assim estabelecidas:

\footnotetext{
As instituições de Educação Superior, por meio dos seus colegiados superiores, devem definir as atribuições e os critérios de constituição do NDE, atendidos, no mínimo, os seguintes:

I - ser constituído por um mínimo de 5 professores pertencentes ao corpo docente do curso;

II - ter pelo menos $60 \%$ de seus membros com titulação acadêmica obtida em programas de pós-graduação stricto sensu;

III - Ter todos os membros em regime de trabalho de tempo parcial ou integral, sendo pelo menos $20 \%$ em tempo integral;

IV - assegurar estratégia de renovação parcial dos integrantes do NDE de modo a assegurar continuidade no processo de acompanhamento do curso (BRASIL, 2010 a ; grifo nosso).
}

O Núcleo Docente Estruturante estudado foi organizado mediante indicação e aprovação de seus integrantes pelo Colegiado de Curso, tendo sido selecionados seis professores doutores do quadro dos cursos em que trabalha(va)m em regime de dedicação exclusiva na instituição. A criação desse Núcleo ocorreu conforme os critérios estabelecidos pela CONAES, em referência à carga horária e à titulação dos professores, evidenciando, desse modo, a reação-resposta ativa de concordância dos professores, que tomaram uma posição a respeito do que é dito no documento (VOLÓCHINOV, 2017).

Todavia, no que se refere ao tempo de permanência dos integrantes no Núcleo, observamos uma discordância dos professores quanto à orientação da CONAES que, no Parecer CNE/CP n. 04/2010, se posiciona, orientando que, "sendo um grupo de acompanhamento, seus membros devem permanecer por, no mínimo, 3 anos e adotada 
estratégia de renovações parciais de modo a haver continuidade no pensar do curso". Por meio da Decisão n. 020/Congregação/IL/2013, de 13 de junho de 2013, a Diretoria do Instituto que abriga os cursos de Letras nomeou os professores com mandato de 2 anos a contar de 30 de janeiro de 2013.

A esse respeito, consideramos que a direção do Instituto poderia até criar "estratégia de renovação parcial" e, com o fim do mandato dos integrantes do NDE, prorrogar o tempo de atuação dos professores por mais um ou dois anos, todavia não teria como garantir a permanência desses docentes no Núcleo por "no mínimo três anos". Isso se verifica devido ao fato de que eles têm a liberdade para decidirem, segundo a própria determinação, se permanecem ou não no grupo. Esse impasse fica evidente quando constatamos que, dos seis professores nomeados para o NDE em 2013, três deixaram de integrá-lo naquele mesmo ano, por razões diversas. Desses, dois foram substituídos em 2014/14 , permanecendo cinco professores no Núcleo.

Assim, por mais que a instituição e os professores dos Cursos de Letras tenham respondido positivamente à CONAES, com a criação do Núcleo Docente Estruturante, a Decisão n. 020/Congregação/IL/2013, assim como as razões que levaram os professores a saírem do grupo, se chocaram contra as forças centrípetas que determinam o tempo de permanência dos integrantes no Núcleo, visando homogeneizar a configuração do NDE no âmbito dos cursos de graduação.

O Instrumento de Avaliação de Cursos de Graduação editado pelo INEP e utilizado pelos avaliadores estabelece como indicador de qualidade do curso a existência do Núcleo Docente Estruturante. Na avaliação in loco dos cursos de Letras ${ }^{5}$, o NDE foi avaliado positivamente, considerando, em uma análise sistêmica e global, os aspectos relacionados à reformulação dos Projetos Pedagógicos dos Cursos.

Analisamos, na seção seguinte, os dados que apresentam a percepção dos sujeitos da pesquisa acerca do Núcleo Docente Estruturante que integram.

\footnotetext{
${ }^{4}$ Em fevereiro de 2014, iniciamos a pesquisa no NDE dos cursos de Letras, encerrando as atividades em maio de 2015, com a greve nacional dos docentes das universidades federais.

${ }^{5} \mathrm{Na}$ avaliação in loco, todos os cursos foram avaliados positivamente, com Conceitos de Cursos (CC) variando de 3 a 5 (sendo 5, perfil de excelência), e, no ENADE de 2014, obtiveram CPC 4.
} 


\title{
3 Núcleo Docente Estruturante: o espaço do embate discursivo
}

Nesta seção, apresentamos a análise dos posicionamentos axiológicos dos integrantes do Núcleo Docente Estruturante (NDE), no que tange à configuração e ao desenvolvimento do Núcleo na instituição estudada, a partir dos dados coletados do questionário aplicado a esses sujeitos e da entrevista coletiva realizada, sem deixar de lado a nossa observação, como pesquisadora, das reuniões de que participamos. Na análise desses dados, voltamos nosso olhar para as palavras, uma vez que as operações discursivas encontram na palavra presente ou ausente um ótimo informante, sendo ela um palco onde se debatem diferentes ideologias (VOLÓCHINOV, 2017).

\subsection{Tensão entre vozes na configuração do Núcleo Docente Estruturante dos cursos de Letras}

A Resolução CONAES n. 1/2010 determina que o Núcleo Docente Estruturante deve ser constituído por um mínimo de

\begin{abstract}
cinco professores pertencentes ao corpo docente do curso, [que] exerçam liderança acadêmica no âmbito do mesmo, percebida na produção de conhecimentos na área, no desenvolvimento do ensino, e em outras dimensões entendidas como importantes pela instituição, e que atuem sobre o desenvolvimento do curso (BRASIL 2010; ; grifo nosso).
\end{abstract}

No glossário que integra o Instrumento de Avaliação de Cursos de Graduação produzido pelo INEP e utilizado por comissões de especialistas para avaliação de cursos, o NDE é definido como

Conjunto de professores, composto por pelo menos cinco docentes do curso, de elevada formação e titulação, contratados em tempo integral ou parcial, que respondem mais diretamente pela concepção, implementação e consolidação do Projeto Pedagógico do Curso (BRASIL, 2015, p.47; grifo nosso).

Tendo em vista tais preceitos, podemos caracterizar essas vozes como forças centrípetas, que agem no sentido de padronizar a estrutura colegiada responsável pelo Projeto Pedagógico de Curso nas instituições brasileiras. Nesse cenário, cada curso, ao 
buscar atender à legislação e ao instrumento do INEP, deve instituir seu NDE com pelo menos cinco professores, os quais devem pertencer ao corpo docente do curso.

Não obstante, na instituição pesquisada, os cursos de Letras criaram um NDE único, constituído por professores com formação específica nas áreas dos cursos de atuação (Português, Literatura, Inglês, Francês e Espanhol), totalizando, assim, cinco membros pertencentes a quadros docentes distintos. Desse modo, o NDE foi constituído por professores que "atuam sobre o desenvolvimento" (BRASIL, 2010b) não de todos os cursos, mas apenas do seu em especial. Tal configuração exigiu que as questões específicas de cada curso fossem discutidas com os seus coordenadores e professores, tendo o representante do NDE como articulador do processo.

Essa característica do NDE é corroborada pelos sujeitos da pesquisa ao apresentarem suas antipalavras à questão pontuada no questionário que visava saber qual era o papel do Núcleo no contexto dos cursos de Letras. Vejamos o que os professores salientaram:

E: Qual o papel do Núcleo Docente Estruturante (NDE) do curso?

P01: Aprimorar o currículo em função de maior qualidade do resultado do ensino (formação de professores).

P02: A criação do NDE no curso de Letras é bastante recente (janeiro de 2013) e estamos ainda tentando entender o que significa ser 'a alma' do curso, função designada ao núcleo pelo documento que estrutura o NDE. Contudo, posso dizer que o NDE ficou encarregado de repensar e reelaborar o novo PPC para o período de 2015-2020 (ainda em elaboração, mas em sua versão quase final). Esse trabalho para mim significou trabalhar com os outros membros do NDE por meio de reflexões coletivas acerca do desenvolvimento do curso de Letras, em busca de sua melhoria envolvendo todos os professores, por meio de consulta às áreas dos quatro cursos de Letras. O NDE é composto pelos representantes de todas as áreas. Cabe ao NDE, portanto, conduzir trabalhos que promovam melhoria para os cursos de Letras.

P03: Apresentar uma proposta de reestruturação do Curso de Letras PortuguêsLiteratura, para rever o perfil do curso e do seu egresso, corrigir distorções, (re)ajustar disciplinas, para atender às exigências do MEC, atualizar conteúdos e bibliografias, com o objetivo de reverter a média 2,0, que o Curso recebeu no ENADE 2011.

P04: Neste momento, estudar alguns fundamentos para uma compreensão mais ampliada da mecânica da matriz curricular do curso de Letras, a fim de reformular o PPC. Naturalmente, para essa finalidade, conta com as discussões e encaminhamentos das áreas componentes do curso.

P05: Por ocasião do mau desempenho dos alunos e, por extensão, dos cursos de Letras na avaliação do ENADE, o NDE teve por papel a condução dos trabalhos de reformulação do Projeto Pedagógico do Curso, discussão junto a alunos e professores e, posteriormente, a implantação, avaliação e acompanhamento do novo PPC. 
P02 destaca que o NDE é composto pelos representantes de todas as áreas. Para esse professor, as atividades do Núcleo significaram trabalhar com os outros membros do NDE por meio de reflexões coletivas, envolvendo todos os professores, por meio de consulta às áreas dos quatro cursos de Letras. P04, nessa mesma direção, acentua que a reformulação do Projeto Pedagógico de Curso (PPC) contou com as discussões e encaminhamentos das áreas componentes do curso que representa. Ao adequarem os preceitos estabelecidos pela Resolução CONAES n. 01/2010 à realidade interna dos cursos, os sujeitos acadêmicos deram voz à defesa de um tipo de organização colegiada formada não por grupos isolados, mas, sim, por um único grupo, com estrutura aberta, de diálogo com os pares. Essa voz pode ser entendida como a voz da autonomia, que assume novas formas de planejar e organizar o trabalho do Núcleo a partir de uma visão da realidade local.

A configuração do NDE, desse modo, projeta o conceito bakhtiniano de força centrífuga, ao evidenciar a posição responsiva de uma comunidade acadêmica que conforma os preceitos legais ao contexto institucional, levando em consideração a realidade do seu quadro de professores, os seus propósitos, desestabilizando, assim, a força centrípeta, que exige das Instituições de Educação Superior (IES) a criação de um núcleo cujo número mínimo de docentes do curso e perfil do grupo são por ela determinados.

Percebemos nesse campo de forças que as ações dos professores representam uma tentativa de sobreviver à homogeneização centrípeta. Por um lado, os cursos se viram obrigados a criar o NDE, já que tal órgão faz parte do processo de avaliação do INEP/MEC, mas, por outro, desgastaram suas determinações, instituindo-o de acordo com a realidade de cada curso, procurando preservar sua singularidade, na diversidade do contexto educacional.

No fragmento em análise, P5 destaca o envolvimento dos alunos na condução dos trabalhos de reformulação do Projeto Pedagógico do Curso. De fato, os professores do NDE organizaram dois encontros com esse segmento, juntamente com os professores dos cursos, para apresentação e discussão da proposta curricular e mudanças previstas para cada curso. Juntamente com Veiga (2012), entendemos que o envolvimento dos estudantes nas questões relativas aos projetos pedagógicos é essencial para um trabalho que se apresenta com perfil descentralizador, dando oportunidade de 
visualização do curso como um todo e possibilitando diálogo pedagógico entre alunos e professores.

Ademais, conforme premissas bakhtinianas, a posição do outro propicia o entendimento do objeto, conferindo-lhe, assim, seu acabamento. Sob este prisma, cada integrante do NDE possui horizontes de valor diferentes em relação à formação docente, mas, quando cada professor apreende as palavras, as posições dos outros sujeitos das instâncias acadêmicas no processo de concepção dos Projetos Pedagógicos, excede o seu próprio horizonte de valor, entra em contato com o horizonte alheio, introduz nele seus acentos e suas expressões, conferindo-lhe, assim, uma feição particular (BAKHTIN, 2014).

Ainda analisando os dados extraídos do questionário, constatamos que o papel do NDE, na ótica dos professores, está voltado para a reformulação dos Projetos Pedagógicos dos Cursos, envolvendo questões relacionadas ao currículo. Para P03, essa atividade é tradutora de uma exigência legal, já que foi realizada com o objetivo de atender às exigências do MEC. Nessa mesma ótica, P5 ressalta o motivo que levou os cursos a reformularem os projetos como sendo o mau desempenho dos alunos e, por extensão, dos cursos de Letras na avaliação do ENADE. Já P1, P02 e P04 não relacionam a atividade a cumprimento de solicitações prescritivas do MEC, como se quisessem assinalar uma ruptura silenciosa com aquele fato que surpreendeu a todos, sem fazer menção a ele (a média 2,0, que o Curso recebeu no ENADE 2011 - P03). Para P01, o papel do NDE é aprimorar o currículo em função de maior qualidade do resultado do ensino.

Por certo, como vimos, o fato de os cursos de Letras da instituição estudada terem sido submetidos a um processo de supervisão especial, decorrente da avaliação considerada insuficiente dos alunos no ENADE de 2011, foi a razão principal que levou os professores a reformularem os Projetos Pedagógicos desses Cursos. Sob essa perspectiva, o Sistema Nacional de Avaliação da Educação Superior (SINAES) acabou impactando os Projetos Pedagógicos dos Cursos e os currículos deles decorrentes, porque mobilizou os sujeitos acadêmicos que foram provocados pela necessidade de atenderem às exigências da política pública.

Considerando as vozes da CONAES, é papel do NDE estabelecer um rumo para o trabalho educativo, determinar diretrizes, fomentar práticas curriculares que 
consolidem o PPC e contribuam para o pleno desenvolvimento do currículo, papel esse traduzido na Resolução CONAES n. 1/2010 da seguinte forma:

\begin{abstract}
São atribuições do Núcleo Docente Estruturante, entre outras:
I - contribuir para a consolidação do perfil profissional do egresso do curso;

II - zelar pela integração curricular interdisciplinar entre as diferentes atividades de ensino constantes no currículo;

III - indicar formas de incentivo ao desenvolvimento de linhas de pesquisa e extensão, oriundas de necessidades da graduação, de exigências do mercado de trabalho e afinadas com as políticas públicas relativas à área de conhecimento do curso;

IV - zelar pelo cumprimento das Diretrizes Curriculares Nacionais para os Cursos de Graduação (BRASIL, 2010a).
\end{abstract}

Os enunciados-respostas dos professores, extraídos do questionário, estabelecem uma relação de assimilação a tais preceitos da CONAES, mais especificamente no que diz respeito às atribuições do Núcleo Docente Estruturante, atinentes à reformulação dos Projetos Pedagógicos dos Cursos. Constatamos, todavia, nesses enunciados-respostas, assim como nas observações in loco que realizamos, que há um silêncio quanto à atribuição disposta no inciso III da Resolução.

Nas expressões discursivas de $\mathrm{P} 02$, podemos encontrar uma possível resposta para esse silêncio dos professores, quando esse docente afirma que a criação do NDE no curso de Letras é bastante recente (janeiro de 2013) e que os integrantes do Núcleo estão ainda tentando entender o que significa ser 'a alma' do curso. Com efeito, o NDE é uma estrutura nova nos cursos, estando ainda em processo de aceitação institucional, de compreensão do papel a ser desempenhado por seus integrantes. Destarte, como todas as políticas educacionais impostas, há também certa resistência por parte da comunidade acadêmica, que enxerga tal imposição com desconfiança.

Ainda assim, esse silêncio dos professores produz outros sentidos. Se esses professores não abordaram a atribuição do NDE descrita no inciso III da Resolução CONAES n. 1/2010, podemos considerar que essa atribuição não entrou em seus horizontes apreciativos de modo significativo a ponto de ser assinalada quando questionados sobre o papel do NDE que integram. Como afirma Volóchinov (2017), o tema e as significações só entram no grupo social quando o grupo começa a valorar esses temas e significações. À vista disso, os integrantes do NDE se apropriam de alguns discursos enquanto outros não entram em seu horizonte apreciativo. Assim, das 
atribuições estabelecidas pela CONAES, as que os professores significaram foi a reformulação dos projetos pedagógicos, aí contida a questão das Diretrizes Curriculares Nacionais e da consolidação do perfil profissional dos egressos dos cursos.

É relevante lembrar também que o NDE ganhou escopo nos cursos de Letras no momento em que os Projetos Pedagógicos desses cursos deveriam ser reformulados, como ação-resposta às determinações do SINAES. Espera-se que, passada essa fase inicial do processo participativo, o próximo passo seja - além da realização de outras ações que contribuam para o desenvolvimento do curso - a implementação, acompanhamento e avaliação desses instrumentos, com a participação e o envolvimento de toda a comunidade acadêmica. Essa expectativa se justifica porque os Projetos Pedagógicos reformulados são mais do que uma formalidade instituída: representam uma reflexão sobre o ensino, a pesquisa e a extensão, uma reflexão sobre a formação docente.

Sob essa ótica, partilhamos com Veiga (2012) a perspectiva de que, independentemente da estrutura colegiada (NDE ou colegiado de curso) à frente do processo de construção dos projetos, faz-se mister que seus integrantes garantam a sua implementação e avaliação, para que esses instrumentos não se tornem apenas peças decorativas, reduzindo-se ao cumprimento de uma tarefa.

P02 chama a atenção para o fato de que os integrantes do NDE estão ainda tentando entender o que significa ser "a alma" do curso, dialogando com o Parecer CONAES n. 04/2010, quando diz que "todo curso que tem qualidade possui (ainda que informalmente) um grupo de professores que, poder-se-ia dizer, é a alma do curso" (BRASIL, 2010b).

Aproximando-nos das considerações de Volóchinov (2017), podemos afirmar que só pode haver compreensão de um texto no diálogo quando se possibilita opor ao autor a sua antipalavra. Se os integrantes do NDE não assimilam as palavras do Parecer CONAES n. 4/2010, para esse grupo tais palavras não passam de palavras alheias, das quais ele não se apropria. Por outro lado, à medida que esse grupo valora, assimila e transforma tais palavras em palavras suas, ele realiza uma compreensão ativa desse discurso, ressignificando-o nas ações do Núcleo.

Constata-se, assim, que o atributo do NDE como "alma do curso", no sentido atribuído pela CONAES, não foi assimilado, ressignificado pelos integrantes do NDE 
dos cursos de Letras estudados. A resposta de P02 evidencia, desse modo, que a instituição do NDE no espaço acadêmico não garante que as prescrições constantes nos documentos oficiais sejam adotadas no sentido proposto por seus mentores.

Por fim, do que discutimos até aqui, podemos afirmar que a Resolução e o Parecer da CONAES, como forças centrípetas, centralizadoras, acabaram provocando um duplo movimento na comunidade acadêmica: por um lado, ela mudou, ao instituir o NDE no âmbito dos cursos, e, por outro, resistiu, devido a forças outras, as centrífugas, que impediram o desenvolvimento pleno dos dispositivos legais.

\subsection{A dinâmica do NDE: uma questão polêmica}

A entrevista realizada de forma coletiva com os sujeitos da pesquisa, responsáveis pela reformulação dos Projetos Pedagógicos dos quatro cursos de Letras da instituição pesquisada, evidencia distintos posicionamentos acerca do modo como deve ocorrer o funcionamento do NDE. Consoante a perspectiva bakhtiniana, vale considerar que a responsividade dos entrevistados se apresenta constitutiva do gênero em questão, no qual os participantes da interação discursiva, ao perceberem o significado linguístico do discurso do outro, concordam com ele, discordam dele, completam-no etc., manifestando, desse modo, aderir ideologicamente a determinados discursos.

O trecho da entrevista abaixo (fragmento 1) apresenta as antipalavras dos professores acerca da dinâmica do Núcleo, que, no fragmento 2, é polemizada. Vejamos, primeiramente, o fragmento 1:

\section{FRAGMENTO 1}

E - As discussões ocorriam apenas no núcleo ou ocorriam em outros espaços também? P02 - Não. Ia tudo pras áreas.

P03 - As reuniões foram basicamente nas áreas. Houve um momento, em que nós nos reunimos com as coordenadoras, mas aí já foi mais pro final. O processo todo se deu mesmo nas áreas.

P02 - Nas áreas, buscamos, conversamos (++) depois nós trazíamos pro núcleo e discutíamos o que cada um tinha conversado, né? E assim nós íamos coordenando. /.../ PO5 - /.../ foi um trabalho, assim, constante de idas e vindas pra discussão de vários tópicos... 
As antipalavras dos professores (ia tudo pras áreas, o processo todo se deu mesmo nas áreas; nas áreas, buscamos, conversamos depois nós trazíamos pro núcleo e discutíamos o que cada um tinha conversado; foi um trabalho, assim, constante de idas e vindas pra discussão de vários tópicos) revelam que o papel do NDE no processo de reformulação dos Projetos Pedagógicos dos Cursos foi democratizar as relações de poder, buscando possibilitar, por sua vez, a participação dos professores, de tal modo que as decisões foram planejadas sem que prevalecesse a hierarquia. Até então, os cursos tinham os projetos pedagógicos elaborados pela coordenação ou por uma equipe do colegiado. Nesse processo, todavia, essa realidade parece ter sido alterada, desenhando outra feição à gestão dos cursos, à medida que a elaboração do instrumento passa a ser responsabilidade de todos.

Em outras palavras, a dinâmica do Núcleo se aproxima do modelo democrático de organização e de gestão, representando uma liderança pedagógica dentro do grupo, uma vez que os membros assumem uma prática descentralizada, buscando um compartilhamento de ações (ANTUNES; PADILHA, 2010). Todavia, esse posicionamento axiológico é contestado por um dos professores, que apresenta um discurso combatido pelos demais membros do grupo, conforme podemos observar no fragmento 2, num momento da entrevista em que os seus integrantes discutiam o que almejavam fazer para a implementação das ações do NDE.

\section{FRAGMENTO 2}

P01 - /.../ iniciamos várias atividades para implementarmos o que sai do núcleo, né? Só que estamos atravessados por um conceito de democracia que não funciona bem na Educação, que é consultar primeiro e depois trazer isso aqui pro núcleo; quando deve ser o contrário, deve ser o que nós discutirmos e combinarmos, como eu sugeri e critiquei de que estávamos nos agarrando muito à burocracia e menos na iniciativa teórica e coisa assim. /.../ A EDUCAÇÃO não funciona assim. Quando é o núcleo que vai propor mudanças curriculares amparadas em teorias, amparadas em práticas, amparadas em documentos oficiais, porque senão os mecanismos que existiam antes do aparecimento do núcleo, teriam prevalecido e ainda, seria, talvez, o colegiado que faria isso, como sempre se fez.

/.../

P04 - O que estou entendendo é assim: a gente aprende a caminhar caminhando. A gente vai pra área porque a gente tá querendo saber como é que faz também. Não adianta. A gente não tem noção pra chegar e falar: VAMOS propor isto. Desculpem. É assim que estou me vendo no processo, né? Há muitas coisas que eu não sei ainda. Eu preciso discutir com a área até pra clarear, pra poder trazer alguma coisa aqui, né? Então eu acho que é um movimento, ainda, de construção. Acho que nós somos novos, ainda. /.../ Mas eu vejo como muito importante o papel desse núcleo. Vejo também e tenho 
respeito, assim, porque TODOS NÓS temos muitas atividades. Pensar em mais essa que não é brincadeira e ainda com muitas perspectivas de aposentadorias aqui na minha área, por exemplo. /.../

P02 - Por isso ((menciona P01)) como era uma coisa muito nova, veio tudo assim. Quando a gente vai ouvir a área, o núcleo vai com uma ideia. /.../É uma coisa que vem por eles, mas, ao mesmo tempo, é uma coisa que nós estamos construindo.

P04 - Uma coisa que senti uma falta tremenda, aí eu achei que a gente colocou os carros na frente dos bois, né? Foi assim: "qual a bibliografia, qual o referencial que vai pautar esse documento?", Nós vamos estudar isso aqui...” Nós refizemos muitas vezes, a gente tinha notícias que tinha que refazer. A gente refazia que era pra tal época. [P02 - Eu também não estou satisfeita com isso daí não] Refazia de novo. Então, acho que isso: faltou um amadurecimento. Assim, vamos estabelecer a bibliografia, a gente estuda isso aí, né, e depois a gente faz. Isso não aconteceu.

E- Mas vocês não fizeram isso em 2013? Não havia uma reunião de discussão?

PO3 - É que no meio do percurso, a gente recebia várias informações, né?

P05 - Ultimatos.

P03 - É.

P05 - Ultimatos, principalmente, que acabaram atrapalhando. Porque houve, sim, um planejamento, nesse sentido. A visão era essa de fazer estudos, primeiro, pra depois passar a fazer alguma alteração. Então, com esses ultimatos que nós tínhamos prazos pra entregar e que precisávamos aprovar, então, isso acabou (++) minando o trabalho. E aí com relação ao que o professor ((menciona P01)) coloca do NDE, eu penso que é importante, sim, nós trabalharmos, irmos às bases, porque não somos soberanos. Nós estamos aqui apenas como (++) representantes também (++) dos nossos colegas (++) que eles têm um conhecimento, porque afinal de contas todos são especialistas em suas áreas.

P01 - Não entendi.

P05 - Não, quando você coloca que nós é que teríamos que determinar, que pensar, propor e não fazer o oposto. Então, eu penso que é um trabalho que ele tem que ser o quê? (++) De mão dupla.

P04- Guimarães já disse: "Só sei que nada sei, mas desconfio de muita coisa". ((todos riem))

O discurso de P01, no fragmento 2, apresenta posição divergente da dos demais professores com relação ao modo como os integrantes do NDE devem desenvolver o seu trabalho. Tal divergência é marcada por um advérbio de negação: estamos atravessados por um conceito de democracia que nãa funciona bem na Educação que é consultar primeiro e depois trazer isso aqui pro núcleo... Nesse enunciado, que responde ativamente às palavras de P02, P03 e P05, apresentadas no fragmento 1, fica clara a acentuação negativa de P01 em relação ao conceito de democracia que circunda o trabalho dos professores integrantes do NDE. A polêmica, nesse caso, mostra claramente o tom discordante e a oposição em relação a esse pensamento. Para o professor, a dinâmica deve ser inversa, ou seja, são os professores do núcleo que devem discutir, combinar para, depois, encaminhar suas propostas aos pares. No plano linguístico, a polêmica aberta é reforçada pelo uso do conectivo "quando", com valor de 
comparação/contraste (...quando deve ser o contrário, deve ser o que nós discutirmos e combinarmos... Quando é o núcleo que vai propor mudanças curriculares amparadas em teorias, amparadas em práticas, amparadas em documentos oficiais...).

Em consequência do posicionamento manifesto por P01, nos enunciados seguintes, constatamos um embate polêmico ao discurso do professor, iniciando com a fala de P04, que começa seu discurso com um enunciado de esclarecimento: $O$ que estou entendendo é assim: a gente aprende a caminhar caminhando. Nessa construção fica sublinhado o pensamento do renomado teórico da educação, Paulo Freire, que afirma: "Ninguém caminha sem aprender a caminhar, sem aprender a fazer o caminho caminhando, refazendo e retocando o sonho pelo qual se pôs a caminhar" (FREIRE, 2000, p.155). A voz do teórico se insere no discurso do professor, que dialoga com as vozes sociais ao dizerem que "vivendo é que se aprende". Em tal enunciado, o discurso do outro é reelaborado, sem que haja o embate discursivo, havendo um efeito de fusão de vozes.

Ao utilizar a metáfora do caminho, P04 deixa entrever que o NDE tem metas a alcançar, horizontes a atingir, mas é preciso passar de uma situação inicial, no princípio do caminho, para uma situação final, após um processo paulatino de envolvimento e desenvolvimento do grupo, ao percorrer tal caminho. O NDE está no estágio inicial (eu acho que é um movimento, ainda, de construção. Acho que nós somos novos, ainda). $\mathrm{E}$ porque se encontra nesse estágio, o professor, de forma incisiva, declara: A gente não tem noção pra chegar e falar: VAMOS propor isto. Desculpem. A afirmação enfática, com a inserção da expressão de "pseudocortesia" "desculpem", marca de forma contundente o ataque ao discurso de P01, quando afirma que é o núcleo que vai propor mudança. Para deixar claro seu posicionamento discordante, P04 utiliza o mesmo verbo usado pelo professor: "propor". Assim, a tomada da fala de P01 como objeto de refutação caracteriza uma polêmica aberta em que o seu discurso se configura predominantemente refratado no discurso de P04.

P04 ainda ressalta a importância do NDE (Mas eu vejo como muito importante o papel desse núcleo) e destaca que respeita o trabalho do núcleo (porque TODOS NÓS temos muitas atividades). Com ênfase na expressão "todos nós" em seu discurso, o professor chama a atenção para a realidade da intensificação do trabalho docente, o qual não vem se restringindo à sala de aula, mas contemplando também as relações com a 
gestão, o projeto pedagógico, a participação nos órgãos acadêmicos, as relações com a sociedade, entre outras funções. Por isso, estar no Núcleo, desenvolvendo mais uma atividade, merece respeito.

Todavia, o professor não deixa de apresentar também sua análise crítica quanto ao trabalho desenvolvido pelo grupo, mobilizando o ditado popular "colocar os carros na frente dos bois" (eu achei que a gente colocou os carros na frente dos bois) para dizer que faltou o estabelecimento de referências teóricas educacionais para pautar a discussão, antes de começarem a elaboração dos Projetos Pedagógicos.

É interessante observar a relação dialógica que se estabelece entre o discurso de P03 e P05 quando justificam o porquê de o núcleo ter colocado "os carros na frente dos bois". P03 afirma que a razão da alteração da ordem foi o fato de o grupo ter recebido várias informações no meio do percurso. Todavia, P05 seleciona um termo ainda mais contundente: ultimatos para o que P03 denomina várias informações, e o sentido do vocábulo selecionado se constrói no todo da unidade do seu discurso. O professor declara que tais "ultimatos" acabaram atrapalhando; que houve, sim, um planejamento, nesse sentido. A visão era essa de fazer estudos, primeiro, pra depois passar a fazer alguma alteração. Mas, porque tinham prazos para entregar os PPCs, tais ultimatos acabaram minando o trabalho.

Na sequência de sua fala, P05 menciona P01, a fim de contestar o seu discurso: E aí com relação ao que o professor coloca do NDE, eu penso que é importante, sim, nós trabalharmos, irmos às bases, porque não somos soberanos. Apesar de P05 não retomar a fala de P01, seu discurso é construído em função do posicionamento do professor. Nessa situação, as expressões "é importante, sim"; "não somos soberanos" marcam a intenção de P05 de sobrelevar seu posicionamento axiológico em relação ao discurso contestado. P05 complementa seu pensamento, afirmando que os membros do NDE estão como representantes de seus pares, que têm um conhecimento, porque afinal de contas todos são especialistas em suas áreas. Todavia, como P05 apenas mencionou P01, mas não retomou explicitamente as suas palavras, o professor expressa não ter entendido a sua fala. P05, então, retoma o discurso do professor, fazendo uso do discurso citado indireto: não, quando você coloca que nós é que teríamos que determinar, que pensar, propor e não fazer o oposto. Dessa forma, P05 deixa mais evidente a polêmica aberta em torno da questão. 
Na mesma direção de P05 e P04, P02 também contesta o discurso de P01, declarando que quando a gente vai ouvir a área, o núcleo vai com uma ideia. /... É uma coisa que vem por eles, mas, ao mesmo tempo, é uma coisa que nós estamos construindo. A antipalavra de P02 reforça o posicionamento de que a participação na reformulação do PPC envolve a partilha de poder na definição dos rumos do curso.

Outro aspecto evidenciado diz respeito à ideia defendida pelos professores de que os membros do NDE precisam consultar as bases porque eles querem saber como é que se faz, porque precisam clarear algumas questões, porque os professores das bases são especialistas em suas áreas. Seus discursos vão de encontro às posições defendidas no Parecer n. 4/2010 da CONAES, que define o perfil dos membros do NDE como pessoas que são referências tanto para os alunos como para a comunidade acadêmica $\mathrm{e}$ que devem ser reconhecidas institucionalmente, para qualificar a concepção, a consolidação e, inclusive, a constante atualização de um projeto pedagógico de curso em geral (BRASIL, 2010b; grifo nosso). Por essa perspectiva do documento oficial, como elucida VEIGA (2012), o PPC é fruto da experiência acumulada e da reflexão sobre ela e é elaborado por um pequeno grupo.

Os discursos dos professores deixam evidente que o processo de (re)formulação de Projetos Pedagógicos de Cursos é muito mais complexo e exige que o instrumento seja produzido e executado na esteira de um movimento participativo. Esse contraste entre o que é definido no documento oficial e a forma como ocorreu o processo de reforma dos PPCs manifestada na fala dos professores e nas respostas dadas ao questionário aplicado reforça nosso entendimento de que o discurso oficial é ressignificado no contexto acadêmico.

\section{Considerações finais}

Neste trabalho, analisamos as reações-respostas dos sujeitos da pesquisa aos discursos oficiais da educação que dispõem sobre o Núcleo Docente Estruturante nas instituições de ensino, focalizando as relações de tensão existentes entre os discursos envolvidos na interação verbal. A pesquisa orientou-se pelos pressupostos teóricoepistemológicos e metodológicos de Bakhtin e o Círculo, o que nos possibilitou compreender os enunciados dos sujeitos da pesquisa em suas dimensões discursivas, 
favorecendo o debate em torno das refrações e revalorizações dos princípios e orientações dos discursos legais relacionados à criação e ao desenvolvimento do NDE no âmbito dos cursos de graduação.

Para a análise dos dados, estabelecemos relações dialógicas entre os discursos dos sujeitos da pesquisa (por meio da análise de enunciados extraídos do questionário de pesquisa e da entrevista coletiva) e os discursos do Parecer CONAES n. 4/2010 e da Resolução CONAES n. 01/2010, que determinam a criação do NDE. A análise dialógica revelou que a posição dos sujeitos em relação ao conteúdo dos documentos a eles endereçado foi de concordância parcial, tanto no que diz respeito à configuração/dinâmica do Núcleo quanto à função dos sujeitos que o integram, mesmo este tendo sido instituído num contexto em que os cursos seriam avaliados por comissões de avaliadores do MEC.

No que se refere ao primeiro aspecto, constatamos que os professores do NDE, em união com seus pares, buscaram uma forma distinta de constituição do núcleo e de desenvolvimento do trabalho, diferindo da proposição dos documentos da CONAES, que apresentam um modelo de grupo mais fechado. A forma como o núcleo foi criado (um único NDE para todos os cursos, com apenas um representante das áreas específicas de cada curso) levou-o a apresentar uma estrutura de natureza aberta, pautada em princípios basilares da gestão democrática - descentralização e participação -, propiciando um espaço de reflexão sobre as realidades internas dos cursos, da instituição.

$\mathrm{O}$ formato do NDE evidencia que os professores resistiram de forma positiva às forças centrípetas. Opor resistência, seja por meio da reavaliação, seja por hibridização ou polemização, dentre vários processos dialógicos, é uma das características das forças centrífugas. Para tanto, no contexto educacional, é necessário o questionamento, sempre, daquilo que está proposto nos documentos oficiais, uma vez que esses enunciados carregam não só possibilidades, como também limitações e contradições.

Quanto à função dos professores do Núcleo, constatamos que os enunciados/discursos dos sujeitos da pesquisa responderam positivamente ao disposto na Resolução CONAES, no que tange à atribuição dos membros do NDE como responsáveis pelo processo de concepção dos Projetos Pedagógicos de Curso. Todavia, os enunciados silenciam sobre a atribuição de "indicar formas de incentivo ao 
desenvolvimento de linhas de pesquisa e extensão, oriundas de necessidades da graduação" (BRASIL, 2010a), estabelecida na Resolução CONAES n. 1/2010 como um dos deveres dos integrantes desse Núcleo. Tal silenciamento revela que essa função não entrou no horizonte valorativo dos sujeitos, preocupados, naquele momento, em reformular os projetos pedagógicos que seriam avaliados pela comissão de especialistas do INEP/MEC. Além desse aspecto, observamos também que o tempo de permanência dos integrantes no grupo não foi seguido conforme estabelecido no Parecer n. 4/2010.

A análise evidenciou também que o processo dialógico de reestruturação dos cursos de Letras não se caracterizou pela harmonia de pensamentos e opiniões; que a participação na reformulação dos Projetos Pedagógicos e a constituição do NDE envolveram embates e negociações, resolvidos a partir de deliberações majoritárias.

Isso posto, pode-se afirmar que os enunciados dos professores do NDE interagem com as vozes oficiais e, de algum modo, são respostas a elas, acolhendo-as, como também alterando-as, recusando-as, desprezando-as. Isso corrobora a nossa compreensão de que as práticas nunca são totalmente reflexos de imposições. Ao contrário, elas resistem, respondem, dizem, desobedecem, desacatam (CERTEAU, 1994).

\section{REFERÊNCIAS}

ANTUNES, A.; PADILHA, P. Educação cidadã, educação integral: fundamentos e práticas. São Paulo: Instituto Paulo Freire, 2010.

BAKHTIN, M. Os gêneros do discurso. In: Estética da criação verbal. Trad. Paulo Bezerra. 6. ed. São Paulo: Martins Fontes, 2011, p.261-306 [1952-1953].

Problemas da poética de Dostoiévski. Trad. Paulo Bezerra. 5. ed. Rio de Janeiro: Forense Universitária, 2013 [1963].

O discurso no romance. In: Questões de literatura e de estética: a teoria do romance. 3. ed. Trad. Aurora Fornoni Bernardini et al. São Paulo: Unesp, 2014 [1934-1935].

BRAIT, B. Análise e teoria do discurso. In: Bakhtin: outros conceitos-chave. São Paulo: Contexto, 2008.

; PISTORI, M. H. C. A produtividade do conceito de gênero em Bakhtin e o Círculo. Alfa, Revista de linguística. [online]. 2012, v.56, n.2, p.371-401. Disponível em: [http://seer.fclar.unesp.br/alfa/article/view/553]. Acesso em: 05 out. 2017.

BRASIL. Lei $N^{o} 10.861$ de 14 de abril de 2004, institui o Sistema Nacional de Avaliação da Educação Superior - SINAES. Disponível em: [http://www.presidencia. gov.br/legislacao]. Acesso em: 02 out. 2014. 
Resolução $N^{o}$ 01, de 17 de junho de 2010 - Comissão Nacional de Avaliação da Educação Superior - CONAES. Brasília, 2010a. Disponível em: [http://portal.mec. gov.br/index.php?option=com_content $\&$ view $=$ article $\& i d=15712 \&$ Itemid=1093].Acesso em: 04 out. 2013.

Parecer N. 4 de 17 de junho de 2010 - Comissão Nacional de Avaliação da Educação Superior - CONAES. Brasília, 2010b. Disponível em: [http://portal.mec. gov.br/index.php?option=com_content $\&$ view $=$ article\&id=15712\&Itemid=1093].Acesso em: 04 out. 2013.

Instrumento de Avaliação de Cursos de Graduação presencial e a distância Instituto Nacional de Estudos e Pesquisas Educacionais Anísio Teixeira (INEP). Brasília: Instituto Nacional de Estudos e Pesquisas Anísio Teixeira, 2015. Disponível em: [ http://portal.inep.gov.br/instrumentos]. Acesso em: 17 mar. 2016.

CERTEAU, M. A invenção do cotidiano: artes de fazer. Petrópolis, RJ: Vozes, 1994.

FARACO, C. Linguagem e diálogo: as ideias linguísticas do círculo de Bakhtin. Curitiba: Criar, 2010.

FREIRE, P. Pedagogia da esperança. São Paulo: Paz e Terra, 2000.

MARCUSCHI, L. A. Análise da conversação. 5. ed. São Paulo: Editora Ática, 2000.

NUNES, J. A. A influência da reação presumida do outro sobre a produção de um enunciado de gênero oficial. Revista Brasileira de Linguística Aplicada. [online]. 2016, vol.16, n.3, p.387-411. Disponível em: [http://www.scielo. br/pdf/rbla/v16n3/19846398-rbla-16-03-00387.pdf]. Acesso em: 17 out. 2017.

Cursos de Letras no centro da arena discursiva da reforma curricular de uma universidade pública mato-grossense. Tese (Doutorado) - Programa de Estudos PósGraduados em Linguística Aplicada e Estudos da Linguagem. Pontifícia Universidade Católica de São Paulo, São Paulo, 2017.

VEIGA, I. P. A. Educação básica e educação superior: Projeto Político-Pedagógico. São Paulo: Papirus Editora, 2012.

VOLÓCHINOV, V. Marxismo e filosofia da linguagem: problemas fundamentais do método sociológico na ciência da linguagem. Trad. Sheila Grillo e Ekaterina Vólkova Américo. São Paulo: Editora 34, 2017 [1929].

Recebido em 06/11/2017

Aprovado em 18/03/2018 